\title{
Will it hurt?
}

A tremendous amount of information will be available at Dentistry 2000 for those who

know how to look for it, and the way to start is to decide what your objectives are so you have a more focused approach to the entire event.
Mike Grace m.grace.bdj@bda-dentistry.org.uk
T his issue of the BDJ includes a special supplement about Dentistry 2000, the main dental event this April that will bring together people from all aspects and pathways in dentistry. Dentistry 2000 includes the societies, associations and people involved in the delivery of dental care to our patients, incorporating a major trade show with the annual conferences of the different associations representing the dental team. In more ways than one it can be said to be a 'family event'.

A lot has already been written about Dentistry 2000 in the pre-publicity and I am sure a lot more will be written afterwards. So, at the risk of adding a further few words to the burgeoning mass already written, I thought it would be pertinent to ask the questions: what is the point and will it be worth it?

To answer the first question, it would be traditional to mention things like meeting with friends, seeing new materials, attending the scientific sessions, browsing the trade show and generally getting involved. After all, that is how most people view conferences and trade shows. But are these real benefits?

Perhaps, instead of describing the traditional reasons for visiting Dentistry 2000 , it would be more appropriate for me to talk about competitive survival in the commercial world. We all know dentistry is changing faster than most of us thought it would, and this means we have to know what is going on if we wish to retain a competitive advantage in attracting patients to our practices and organisations. If we do not continue to attract patients they will spend their cash elsewhere, whether on dental care with someone else or other (more attractive) goods and supplies.

Thus, in order to attract patients we need accurate and relevant knowledge when setting our strategic and marketing plans. Knowledge helps us to estimate what we think is going to happen in the future so that we can continue to attract people to our practices and continue to offer the services and products they are likely to buy.

Let me provide some solid examples. What technological advances are likely to occur in dental materials that enable us to offer improved aesthetics? How will the expanding digital revolution change the way our patients interact with us? How will the growth of bodies corporate influence the expectations of our patients? Will the changes occurring in dental education and the development of the dental team affect the way we provide dental care, and how can we plan the development of our role in the dental practice to embrace those changes? What will specialisation mean to our own objectives?

How much time we spend considering these questions and the actions we take will have a direct influence on the success we have in achieving our personal and business objectives - whoever we are. What is certain is that the more knowledge we have the better the chance of our predictions being correct.

Collecting this kind of knowledge is difficult and time-consuming - or at least it would usually be. The good news is that a tremendous amount of information will be available at Dentistry 2000 for those who know how to look for it, and the way to start is to decide what your objectives are so you have a more focused approach to the entire event. That way you can truly come away from the whole thing with a much clearer idea of how the dental world is likely to change and how it impinges on your own plans for the future. And that should answer the second point I mentioned above about whether attending Dentistry 2000 would be worthwhile.

$\mathrm{Oh}$ - and you might meet a few friends, see a few new materials and listen to the occasional lecture as well. 